\title{
EL DERECHO DEL CONSUMO COMO CATEGORÍA AUTÓNOMA. SU EVOLUCIÓN YFISONOMÍA
}

Fecha de recepción: 26-06-2009, aprobación: 12-08-2009

Juan Carlos Villalba Cuéllar

\section{RESUMEN}

La protección al consumidor ha penetrado el Derecho de tal manera, que hoy se puede hablar del Derecho del consumo como una categoría jurídica especial. En Colombia, sin embargo, esta tendencia no ha logrado permear las instituciones jurídicas de una manera clara, y aún se conserva una legislación poco idónea para resolver las vicisitudes que la complejidad de los mercados impone a este grupo de personas denominadas consumidores, en el mundo actual. Este artículo tiene por finalidad demostrar que el Derecho del consumo es una perspectiva del Derecho que tiene una fisonomía propia e involucra los aspectos más debatidos del Derecho privado y del Derecho de la empresa, tales como la responsabilidad por productos defectuosos, la protección a la formación del consentimiento y la publicidad engañosa, entre otros. Para cumplir el objetivo se aborda primero la evolución de la protección a los consumidores en el Derecho comparado, para en segundo lugar caracterizarlo y, finalmente, delimitar el Derecho del consumo, de tal forma que se puedan saber cuáles son su contexto y alcances.

\section{PALABRAS CLAVE}

Derecho del consumo, protección al consumidor.

\section{ABSTRACT}

The protection to consumers is so embedded into law that nowadays it is possible to talk about consumer rights as a special legal category. However, in Colombia this tendency has not permeated legal institutions clearly, and there is not a suitable legislation to solve the vicissitudes imposed by the complexity of the markets to the consumers nowadays. This article shows that consumer rights are a perspective of the law that have their own physiognomy and involve the most debated aspects of current private law and business law. Some examples of these are: responsibility for products with flaws, protection to consent training, and misleading publicity, among others. In order to do this, this article deals first with the evolution of the consumer protection and then to characterize it, and finally to define the consumer right in such a way that its context and scope are well-known.

\section{KEYWORDS}

Consumer Law, protection to consumers. 


\section{INTRODUCCIÓN}

En el contexto colombiano hacer referencia al Derecho del consumo todavía resulta algo extraño y hasta la doctrina al respecto resulta escasa. Algunos autores que se ocupan del Derecho de la competencia hacen mención del tema, pero lo dejan como secundario, los manuales de obligaciones y contratos lo ignoran y la jurisprudencia brilla por su ausencia. Existe doctrina de la Superintendencia de Industria y Comercio, entidad encargada de vigilar la protección al consumidor, consistente en conceptos emitidos durante los últimos años. En igual forma, las resoluciones emitidas por esta entidad ayudan a clarificar algunos aspectos de la aplicación de la normatividad vigente en Colombia sobre el tema.

En este orden de ideas, hay algo que llama la atención: mientras el Derecho del consumo en el Derecho comparado ha tenido un papel protagónico y unos avances importantes, por ejemplo en el contexto del Derecho comunitario europeo, en el ordenamiento jurídico colombiano y en la academia parece que el tema no genera mayor interés. Sin embargo, en foros de discusión, en especial sobre Derecho privado, algunos

\section{RESEÑA DE AUTORES}

\section{Juan Carlos Villalba Cuéllar}

juan.villalba@umng.edu.co; jvillalba_cuellar@yahoo.com Abogado, docente e investigador; miembro de la línea en Derecho económico y de los negocios, grupo en Derecho privado del centro de investigaciones de la Facultad de Derecho de la Universidad Militar Nueva Granada y director de postgrados de la Facultad de Derecho de esa misma universidad. Magíster IIm en Derecho francés, europeo e internacional de negocios, de la Universidad Panthéon-Assas Paris II y el Instituto de Derecho Comparado de París (Francia). Especialista en docencia universitaria. Profesor de la Facultad de Derecho del Politécnico Grancolombiano. temas que son propios del Derecho del consumo ya se comienzan a debatir, sin que en algunos casos sus expositores tengan claros el origen y la ubicación de dichas problemáticas.

Frente a este fenómeno podemos hacer varias conjeturas. Una podría consistir en que en este país, a diferencia del resto del mundo, los consumidores no tienen problemas y, por tanto, no existe una necesidad real de protegerlos. Esta proposición no resiste mayor análisis y debe ser descartada.

La segunda sería que la legislación existente al respecto en Colombia es suficiente, se encarga de proteger debidamente a los consumidores y, por ello, no es necesario promover nuevas normas, pues frente a temas como la regulación de contratos con consumidores, la protección de la formación del consentimiento en contratos de consumo, la publicidad desleal y las cláusulas abusivas, todo está dicho o, más bien, no es necesario decir nada. Ante esta segunda hipótesis se considera que si bien es cierto que existe legislación protectora de los consumidores en el ordenamiento jurídico colombiano, esta no es suficiente y debe ser mejorada, ya que en los últimos años el mercado interno colombiano ha sufrido grandes cambios, como producto, por ejemplo, de la celebración de tratados de libre comercio, concentración de los mercados e ingreso de grandes multinacionales al país.

En tercer lugar, si bien se reconoce la importancia de algunos temas propuestos, no se acepta que el tema de la protección al consumidor merezca ser categorizada como una especie de Derecho, el Derecho del consumo; se trata más 
bien de un aspecto propio de un estatuto y algunas normas dispersas, un Derecho sin cuerpo propio, una especie de Derecho de tercera, insignificante, para ciudadanos de tercera. Con relación a esta hipótesis se debe afirmar que sí se trata de un nuevo Derecho, el cual encuentra justificación de raigambre constitucional, y que las normas de protección al consumidor no son normas de tercera categoría, fútiles, sino que se trata de normas importantes que han logrado permear muchas ramas del Derecho.

Todo este fenómeno puede encontrar explicaciones. En primer término, una no jurídica, de orden social, consistente en que en Colombia no existe una cultura del consumo - del consumo responsablesino más bien del consumismo; es decir, de consumir por consumir, lo que a su vez ha conllevado a cierto conformismo del consumidor, que no reclama, no conoce sus derechos, ni le interesan, y no denuncia. La explicación jurídica consiste en que la normatividad colombiana no ha promovido ni facilitado la creación de una cultura del consumo responsable, no ha creado una conciencia de consumidor en el ciudadano, ni le ha brindado los medios a los ciudadanos para que defiendan sus derechos. En todo caso, en Colombia algo está fallando frente al tema de la protección al consumidor, y la legislación y las autoridades tienen un grado de responsabilidad al respecto.

Este artículo tiene como finalidad hacer un esquema, un esbozo, de lo que es el Derecho del consumo y explicar su evolución, su razón de ser, sus características, su campo de acción, de tal forma que no queden dudas acerca de la consideración de este
Derecho como uno importante, moderno y necesario en las relaciones jurídicas modernas, para tratar de combatir la aparente displicencia y el papel secundario que se le ha dado en el contexto colombiano.

El plan es abordar primero la evolución del Derecho del consumo moderno, sin remitirse a antecedentes lejanos, que sin duda existen, para darle lugar a la definición y caracterización del Derecho del consumo y, al final, tratar su delimitación y campo de acción.

\section{HISTORIA Y EVOLUCIÓN}

El Derecho del consumo es una categoría jurídica reciente, que hizo su aparición como consecuencia de la necesidad de regular las relaciones jurídicas de los ciudadanos cuando estos actúan en el mercado bajo ciertas circunstancias. Se habla hoy de los consumidores como un grupo específico de personas que son objeto de protección por parte del legislador. El consumidor, como sujeto jurídico, hizo su aparición en la medida en que los países occidentales iban alcanzado grados avanzados de capitalismo, pues hasta entonces el destinatario de productos o servicios era solo el eslabón final del sistema, y era digno de atención únicamente como "metro" de valoración del comportamiento del homo oeconomicus, como mero espectador externo de ciertas acciones, con una participación únicamente final (Alpa, 2006).

Esa necesidad de protección se hizo patente en el siglo pasado, cuando en la sociedad estadounidense se conformaron asociaciones con la finalidad de proteger los intereses de los consumidores. Algunos hombres políticos asumieron las banderas de la protección a los consumidores. Es recordado en el contexto de los Estados
El Derecho del consumo es una categoría jurídica reciente, que hizo su aparición como consecuencia de la necesidad de regular las relaciones jurídicas de los ciudadanos cuando estos actúan en el mercado bajo ciertas circunstancias. 
Después de la Segunda Guerra Mundial,

Estados Unidos vivió una

época de gran prosperidad, en la que sus

ciudadanos

consumían en exceso carros, electrodomésticos, entretenimiento, etcétera.
Unidos el discurso que el 15 de marzo de 1962 pronunciara el presidente Kennedy, en el cual afirmaba que todos somos consumidores y defendía el derecho que tienen los consumidores a ser informados, el derecho a la seguridad, el derecho a escoger y ser oídos.

En efecto, fue en el ámbito de Estados Unidos que la normatividad de protección al consumidor se desarrolló. Estos movimientos fueron denominados consumeristas. Tres movimientos de aquellos se distinguieron en Estados Unidos, principalmente en las décadas de los años 1900, 1930 y 1960. El primer movimiento se dio en la administración del presidente Teodoro Roosevelt, de 1901 a 1909, aunque ya existía un antecedente, pues en la década de 1890 se presentaron varios proyectos de ley por parte de abogados defensores de los consumidores, que denunciaban el uso de aditivos y preservativos peligrosos para el hombre en la industria alimenticia, pero fueron derrotados. En el gobierno de Roosevelt se aprobó el Pure Food and Drug Act de 1906, como consecuencia de graves denuncias efectuadas por periodistas, escándalos en materia de farmacéuticos (Ovalle, 2000) y los escritos polémicos de Upton Sinclair, quien en 1906 publicó The Jungle, un texto en el que este socialista denunciaba graves irregularidades en plantas de procesamiento y empaque de alimentos en Chicago (Alpa, 2006). Esta ley creó un sistema de inspecciones oficiales en plantas procesadoras de alimentos. En 1914 fue creada la Federal Trade Commission, entidad encargada de regular la competencia en el mercado y velar por mantener el mercado libre de engaños. En la década de 1920 la consolidación del automóvil como medio de transporte y el fortalecimiento de los medios publicitarios que promovían un estilo de vida americano aumentaron el consumismo. Entre 1920 y 1930 se produjeron envenenamientos y desfiguraciones ocasionadas por cosméticos y muertes a causa del uso de medicamentos.

El segundo movimiento de protesta de los consumidores se dio a mediados de los años treinta, por causa del aumento excesivo de los precios, en medio de la crisis económica mundial conocida como la Gran Depresión, la huelga de las amas de casa en Detroit y el escándalo de la sustancia sulfanilamida (Ovalle, 2000). Como resultado, el gobierno de Franklin D. Roosevelt, en 1938, aprobó una ley que fortalecía el Pure Food and Drug Act y le daba nuevos poderes a la Federal Trade Commission para combatir la publicidad engañosa. Rexford G. Tugwell, asistente de la Secretaría de Agricultura del gobierno del presidente Roosevelt, inició campañas de denuncia de sustancias peligrosas y promovió el cambio de legislación en materia de alimentos, medicamentos y cosméticos (Durand, 2007). Después de la Segunda Guerra Mundial, Estados Unidos vivió una época de gran prosperidad, en la que sus ciudadanos consumían en exceso carros, electrodomésticos, entretenimiento, etcétera.

En la mitad de la década de los años sesenta se presentó el tercer movimiento, gracias al impulso que le dio el presidente Kennedy en el ya referido discurso y la promulgación de la carta de derechos de los consumidores. Asimismo, a la labor de activistas como el abogado Ralph Nader, quien en 1965 publicó el libro Unsafe at Any Speed, en el que revelaba graves irregularidades en la industria automotriz que se preocupaba más por el diseño y la comodidad 
de los automóviles que por la seguridad. La bióloga Rachel Carson publicó en los años sesenta el libro Primavera silenciosa, en el cual documentaba la utilización de algunos plaguicidas que contaminaban la cadena alimentaria y generaban enfermedades en los seres humanos, lo cual influyó, en parte, en la creación en 1970 de la Agencia para la Protección Ambiental.

La sociedad estadounidense se hizo consciente de la necesidad de promover la protección al consumidor, en la medida en que el país se iba consolidando como una potencia industrial, que la capacidad adquisitiva de los ciudadanos era más alta y que grandes industrias de ese país se posicionaron en los mercados mundiales. En el país modelo de capitalismo, la necesidad de hacer contrapeso al ímpetu de la sociedad de consumo dio lugar a la aparición de legislación y entidades protectoras de los intereses de los consumidores.

En la década de los años sesenta, en el contexto de la Comunidad Económica Europea (hoy Unión Europea), se comenzó a legislar en materia de protección al consumidor. El Tratado de Roma de 1957 no hace referencia a la protección al consumidor; sin embargo, no se puede desconocer que este es un actor esencial del mercado y que debe ser protegido, con miras a alcanzar las cuatro libertades fundamentales en que se basa hoy en día el mercado común. El texto original del tratado no se ocupaba directamente de este tema; Calais (2006: 40) afirma que para esa época el desequilibrio entre productores y consumidores no era claramente percibido.

En el año 1972, en un encuentro de jefes de Estado y de gobierno reunidos en París, se determinó que la Comunidad debería ir más allá de la expansión económica y propender por el mejoramiento de las condiciones de vida y de trabajo de sus ciudadanos, para lo cual deberían acogerse nuevas políticas que permitieran el avance de las medidas adoptadas para proteger a los consumidores. En el año 1975 se presentó un "programa preliminar de la CEE para una política de protección y de información a los consumidores", que se refería a cinco derechos fundamentales de los consumidores: el derecho a la protección de la salud y la seguridad; la protección de sus intereses económicos; la reparación de los daños; la información y la educación y el derecho a ser oído. Este programa fue seguido por otro, en 1981, y por uno más, el de 1986, para dar "un nuevo impulso de una política de protección y promoción de los consumidores" (Calais, 2006: 40-41). En general, según Poillot (2006: 43-44), puede afirmarse que la protección al consumidor en el ámbito comunitario europeo tiene dos grandes etapas: la época anterior al Tratado de Maastricht (1992), que sirvió gestación al Derecho del consumo comunitario en aras de lograr la consolidación del mercado interior, y la posterior a ese mismo tratado, cuando la Unión Europea asume una política clara de protección al consumidor y define la necesidad de unificar y armonizar las normatividades nacionales sobre la materia, como un punto clave para el desarrollo del mercado interior.

El Tratado de Maastricht, título XI denominado "Protección de los consumidores", se refirió por primera vez a ellos, y en 1997 el Tratado de Ámsterdam modificó este artículo para convertirse en el artículo 153 del actual Tratado CE, que dice: 
1. Para promover los intereses de los consumidores y garantizarles un alto nivel de protección, la Comunidad contribuirá a proteger la salud, la seguridad y los intereses económicos de los consumidores, así como a promover su derecho a la información, a la educación y a organizarse para salvaguardar sus intereses.

2. Al definirse y ejecutarse otras políticas y acciones comunitarias se tendrán en cuenta las exigencias de la protección de los consumidores.

3. La Comunidad contribuirá a que se alcancen los objetivos a que se refiere el apartado 1 mediante:

a) medidas que adopte en virtud del artículo 95 en el marco de la realización del mercado interior;

b) medidas que apoyen, complementen y supervisen la política llevada a cabo por los Estados miembros.

4. El Consejo, con arreglo al procedimiento previsto en el artículo 251 y previa consulta al Comité

Económico y Social, adoptará las medidas mencionadas en la letra b) del apartado 3.

5. Las medidas que se adopten en virtud del apartado 4 no obstarán para que cada uno de los Estados miembros mantenga y adopte medidas de mayor protección. Dichas medidas deberán ser compatibles con el presente Tratado.

El artículo 30 del tratado se refiere a la protección de la salud y la vida de las personas, en el que se sienta uno de los pilares fundamentales del Derecho del consumo: el derecho a la seguridad. Por otro lado, los artículos 33, 34 y 82 se refieren, en materia de política común, a "asegurar al consumidor suministros a precios razonables", a la exclusión de "toda discriminación entre productores y consumidores de la comunidad" y a la "limitación de la producción, el mercado y el desarrollo técnico en perjuicio de los consumidores".
En igual medida, la Carta de derechos fundamentales de la Unión Europea consagró como principio, "asegurar un nivel elevado de protección a los consumidores". La Corte de Justicia de las Comunidades Europeas ha desempeñado un papel muy importante en la aplicación e interpretación de la normatividad europea en materia de protección al consumidor.

Después de haberse aceptado la protección a los consumidores como un principio necesario para el desarrollo de la integración económica y social, el Derecho europeo del consumo se fue construyendo a partir de directivas que contribuyeron a la armonización de este Derecho en los diferentes Estados de la Unión Europea. En distintos ámbitos se fueron creando directrices comunes, tales como la protección de la salud y la seguridad, la protección de intereses económicos de los consumidores (publicidad engañosa, venta a distancia, ventas a crédito, cláusulas abusivas, prácticas comerciales agresivas y desleales, entre otros), la reparación de daños sufridos por los consumidores y la información dada a los consumidores, principalmente.

En paralelo se encuentra que los Estados miembros fueron adecuando sus normatividades internas a las exigencias de las directivas europeas, consolidándose un nivel de protección al consumidor armonizado legalmente, cada cual a su manera. Por ejemplo, algunos países como Francia e Italia crearon sus propios códigos del consumo, en otros, como España, se mantiene la ley de defensa del consumidor (LGDC) de manera independiente, y en Alemania, en la última reforma al código civil (вGB, por su sigla en alemán) de 2003, se integró esta normatividad en 
el régimen general de las obligaciones y los contratos.

En Colombia, la Ley 73 de 1981 facultó al Presidente de la República para expedir normas sobre responsabilidad de los productores en la idoneidad de los bienes y servicios que se ofrecen en el mercado, por la información ofrecida a los consumidores y la prestación de servicios que requieren el depósito de los bienes de propiedad de los usuarios, entre otros. En virtud de esta ley, el gobierno expidió el Decreto 3466 de 1982, conocido como Estatuto del Consumidor, en el cual se desarrollan las materias citadas por la Ley 73. Otras normas, como el Estatuto Orgánico del Sistema Financiero, se ocupan del tema.

\section{EL DERECHO DEL CONSUMO}

\section{DEFINICIÓN}

El Derecho del consumo es, según Pérez Bustamante (2004: 2), aquel que regula los intereses de los consumidores y las relaciones de consumo en general. Aunque no son comunes las definiciones del Derecho del consumo, esta se considera acertada, pues la finalidad es la regulación de todas las situaciones jurídicas que pongan en juego los intereses de los consumidores. Para Calais-Auloy (2006: 18), el Derecho del consumo está constituido por reglas que responden a dos criterios fundamentales: (a) su aplicación está reservada a relaciones entre profesionales y consumidores y (b) su finalidad es proteger a los consumidores. Aunque para este autor la concepción debe ser más extensa, pues en algunos casos el Derecho del consumo cobija aspectos que se aplican de manera general, tales como la responsabilidad por productos defectuosos y la publicidad enga- ñosa. En este orden de ideas, el Derecho del consumo hace su aparición cuando en cualquier relación jurídica obligacional de naturaleza contractual se encuentre un consumidor en uno de los extremos. Esta relación jurídica ha sido denominada por la doctrina como la relación de consumo, constituida por un consumidor y un productor (o profesional).

Se ha tratado de justificar, en general, la existencia del Derecho del consumo como un Derecho proteccionista de la persona en estado de debilidad -el consumidorfrente a otra que se encuentra en posición de dominio con respecto a este-el productor-, creándose una relación entre buenos y malos, que ha generado malestar en ciertos doctrinantes como Rubio (2007: 472), que al respecto manifiesta:

Cuando la concepción de los temas de consumidor se enfoca en la expedición de estatutos o normas que buscan generar limitaciones, restricciones, obligaciones y sanciones, tal concepción parte de una premisa básica, y es que existen unas personas débiles (consumidores) que deben ser defendidas de otras fuertes (productores y vendedores): Esta visión se estructura en una contraposición de fuerzas disparejas, que de alguna forma debe ser nivelada mediante la intervención de un sujeto poderoso (Estado) que no solo nivele las cargas, sino que además castigue a los "malos". Bajo estos parámetros, las relaciones que se generan son de contienda entre buenos y malos, o débiles, fuertes y más fuertes.

En lo absoluto. Esta concepción debe ser atemperada, puesto que el Derecho del consumo no busca estigmatizar a alguna de las partes de la relación jurídica, sino más bien corregir los desequilibrios que se presentan eventualmente en esta y darle al consumidor
El Derecho del consumo es, según Pérez Bustamante (2004: 2), aquel que regula los intereses de los consumidores y las relaciones de consumo en general. 
Debe tenerse encuentaque el Derecho del consumo no se reduce al Estatuto de Protección al Consumidor, sino que existe una extensa normatividad en la cualse encuentran disposiciones sobre el tema. una herramienta para lograr la protección de los derechos que tiene en calidad de tal. El consumidor no necesariamente está en posición de debilidad ni debe ser considerado un ser inferior; por el contrario, la tendencia en el Derecho moderno es tomarlo como una persona medianamente informada y perspicaz, lo cual se ha hecho palpable en numerosos fallos del Tribunal de Justicia de las Comunidades Europeas (TJCE), tales como las sentencias Gut Springenheide y Darbo TJCE (al igual que las sentencias TJCE 126-91, 315- 92, 456-93, 470-93, 239-90, 132-03, 169-99, 212-03, 358-01, 99-01 y 104-00), así como en algunos reglamentos comunitarios (González, 2007: 9-19). Sin embargo, la mentada asimetría en las relaciones de consumo no es una ficción; la regla general es que el productor tiene a su disposición una serie de herramientas que le permiten adquirir una ventaja frente al consumidor, tales como la publicidad, las técnicas de marketing y de ventas, la posibilidad de establecer las reglas generales de contratación, etcétera.

En síntesis, el Derecho del consumo no pierde su neutralidad ni su eficiencia por el hecho de ser proteccionista del consumidor, porque este corrige situaciones anómalas excepcionales que perjudican a este último. Por esta misma razón los estatutos de protección al consumidor no son Códigos Civiles o de Códigos de Comercio paralelos, ya que sólo regulan algunas materias o situaciones en que se considera que eventualmente el consumidor puede verse en desventaja, por ejemplo, el deber de información en el etiquetaje de productos.

\section{CARACTERÍSTICAS DEL DERECHO DEL CONSUMO}

Con fundamento en la cantidad de materias que el Derecho del consumo regula y el desarrollo legislativo que ha tenido en el mundo, podemos acercarnos a delinear lo que caracteriza al Derecho del consumo.

\section{a. Es Derecho transversal}

No se trata de una nueva rama del Derecho, ni mucho menos lo podemos incluir dentro del Derecho privado o del Derecho público, porque el Derecho del consumo corta transversalmente el ordenamiento jurídico (Rivero, 1997: 33). Debe tenerse en cuenta que el Derecho del consumo no se reduce al Estatuto de Protección al Consumidor, sino que existe una extensa normatividad en la cual se encuentran disposiciones sobre el tema, tales como el Estatuto Orgánico del Sistema Financiero, la ley de servicios públicos domiciliarios y regulación en materia de seguros, transporte y salud, entre otros.

\section{b. Es un Derecho pluridisciplinario}

Esta característica está intrínsecamente relacionada con la anterior, ya que el Derecho del consumo no se inscribe dentro de la clasificación de las disciplinas jurídicas tradicionales: Derecho penal, civil, administrativo, etc. El Derecho del consumo hace parte de una nueva categoría de disciplinas jurídicas que atraviesa las demás, tales como el Derecho de la competencia, el Derecho del medio ambiente y el Derecho de la empresa, entre otras. Durand Carrión (2007: 57) afirma sobre este tema:

El hecho de que los intereses de los consumidores ofrezcan una diversa naturaleza en cada uno de los momentos del proceso económico (producción, transporte, comercialización, oferta, venta y postventa y consumición o utilización) explica el carácter pluridisciplinario de la 
tutela jurídica del consumidor, por cuanto que la naturaleza de las normas jurídicas protectoras de los intereses de los consumidores varía en cada uno de esos momentos del proceso económico (normas civiles, mercantiles, administrativas, económicas, penales, de policía, de mercado, etc.).

El Derecho del consumo tiene que ver con las siguientes ramas del Derecho:

El Derecho civil, porque las relaciones de consumo dan lugar en la mayoría de los casos a contratos de Derecho privado (Calais, 2006: 19) que implican la aplicación de aspectos como los vicios del consentimiento, los vicios ocultos de la cosa vendida y la responsabilidad civil. El Derecho del consumo se integra en el Derecho civil al reemplazar, algunas veces, las reglas del Derecho común para darle paso a reglas de carácter especial; por ejemplo, en materia de relaciones contractuales, el Derecho de retracto reemplaza las normas generales del contrato del Código Civil en lo atinente a la ruptura unilateral del contrato.

El Derecho comercial. Algunas disposiciones del Derecho del consumo imponen obligaciones específicas a los comerciantes, como el deber de información en materia de fijación de precios, publicidad y etiquetaje, así como el deber de garantía sobre los productos vendidos. Debe observarse, también, que la relación de consumo está conformada por un productor y un consumidor, en la que el primero, en todos los casos, es un comerciante, por lo cual se puede afirmar que los contratos de consumo son contratos que tiene vocación a que la norma comercial se aplique de forma general; de manera especial se aplicará la norma del consumo. Por tanto, en materia de contratos comerciales no debe perderse de vista que el Derecho del consumo muchas veces estará presente. Otras ramas del Derecho comercial encuentran afinidad con el Derecho del consumo. Ello sucede principalmente con el Derecho de la competencia, que al regular los comportamientos de los agentes del mercado tiene en cuenta al consumidor, por tratarse del eslabón final de la cadena productiva, de un agente económico que demanda bienes y servicios que se ofrecen en el mercado. El Derecho financiero es otro ejemplo de ello. No se puede olvidar que el Derecho comercial es el Derecho de los comerciantes y se focaliza en los actos de comercio; sin embargo, en algunos aspectos de su interés, se relaciona con el Derecho del consumo.

El Derecho administrativo. En la mayoría de los casos existen autoridades encargadas de velar por el cumplimiento de las normas de protección al consumidor. En Colombia, la Superintendencia de Industria y Comercio tiene a su cargo esta labor, la cual ejerce desde la Delegatura para la Protección al Consumidor. Esta competencia implica que se investiguen las infracciones a las normas y se impongan sanciones administrativas mediante procedimientos administrativos. Además, en el ejercicio de la protección al consumidor se verán siempre involucradas entidades de naturaleza pública o que desarrollan actividades de interés colectivo; por ejemplo, empresas prestadoras de servicios públicos, entidades financieras, hospitales y empresas de transporte, entre otras.

\section{c. Es Derecho económico}

El Derecho del consumo hace parte de lo que se conoce hoy en día como Derecho económico, el cual, según Márquez (2007: 
El Derecho del consumo rompe con el esquema tradicional que concibe la igualdad de los individuos en las relaciones jurídicas.
15), abarca el conjunto de normas jurídicas de contenido económico que tienen como finalidad regular la economía, para alcanzar un punto de equilibrio que la haga lo más eficiente posible. Según este autor,

En materia económica la protección al consumidor se requiere por la asimetría de la información que puede haber antes de la realización del negocio, y en el daño al mercado proveniente de los costos de transacción tan altos a los que deberían someterse los consumidores, entre ellos la obtención de la información principalmente. En un mercado de competencia perfecta, la información de los agentes es completa, es decir, todos los agentes tienen acceso a toda la información del mercado. Esta información completa se transmite a través del precio de los bienes y de los servicios. Si el mercado no es de competencia perfecta, y especialmente cuando tal causa está dada por la asimetría de la información debido a la información incompleta, se genera una posición de dominio de las que es fácil abusar por parte del conocedor de la información. El Estado debe corregir esta falla del mercado buscando eliminar las fortalezas adquiridas por los tenedores de la información cuando tal situación perjudique al mercado (Márquez, 2007: 209).

\section{d. Es un Derecho especial}

Frente a las ramas del Derecho tradicionales como el Derecho civil, comercial y administrativo, entre otras, el Derecho del consumo es de carácter especial y, por tanto, su aplicación es preferente frente a normas de carácter general.

\section{e. Es un Derecho proteccionista}

El Derecho del consumo rompe con el esquema tradicional que concibe la igualdad de los individuos en las relacio- nes jurídicas. En materia contractual, las relaciones de consumo son consideradas asimétricas porque el consumidor es la parte débil del vínculo obligacional. En algunos casos se considera que el productor o prestador del servicio se encuentra en posición de dominio contractual frente a su contratante. Por ejemplo, en el ámbito colombiano, la ley de servicios públicos domiciliarios, en su artículo 14.13, define la posición dominante como la que tiene una empresa de servicios públicos con respecto a sus usuarios, y la que tiene una empresa con respecto al mercado de sus servicios y de sus sustitutos próximos, cuando sirve al $25 \%$ o más de los usuarios que conforman el mercado.

El postulado de la autonomía de la voluntad privada sufre una derogación en esta materia, porque, frente a contratos de consumo, el legislador interviene a favor del consumidor, a pesar de que este se hubiere obligado en uno u otro sentido, de modo tal que quien dice contractual no dice justo. En este sentido, Mosset y Lorenzetti (1993: 22) señalan:

La aparición del 'Derecho de la Consumición'. Fue un imperativo de la observación acerca del tráfico entre empresario y consumidor. En esta relación los postulados de libertad y autonomía contractual quedan muchas veces afectados. La fraternidad se desdibuja, la igualdad, en situaciones plurales, desaparece. Tal y como observa Reich, en la doctrina alemana, 'los principios civilísticos tradicionales no son suficientes y deben, como en el Derecho del Trabajo, buscarse otras soluciones para relativizar el desnivel de poder entre el empresario y el consumidor'. 
Puede observarse que la mayoría de tratadistas justifica la existencia del Derecho del consumo en el interés proteccionista sobre los consumidores, dadas las condiciones de los mercados en la actualidad. Marco Velilla (2001: 154), en lo atinente a la razón de ser del Derecho del consumo, señala que:

Aunque el equilibrio contractual ha sido una preocupación constante en el Derecho de los contratos, la profunda transformación en las condiciones de la producción y de la distribución ha generalizado la celebración de contratos en los cuales el consumidor tiene que aceptar o rechazar en bloque las condiciones del contrato, sin tener la posibilidad de discutirlas con quien ha preestablecido el contrato (contratos de adhesión), quien puede incluso llegar a abusar de su poder, fabricando el contrato a su medida o incluyendo sólo las cláusulas que le sean más favorables.

Se puede afirmar que el carácter proteccionista del Derecho del consumo ha permeado necesariamente el Derecho de los contratos, por lo cual se habla de una nueva categoría de contratos: los contratos de consumo.

\section{f. Sus normas son de orden público}

Las normas del Derecho del consumo son, por regla general, de orden público, de tal forma que no pueden ser derogadas por la voluntad de los particulares. Esta característica encuentra su razón de ser en que un estatuto proteccionista no cumpliría su finalidad si su aplicación dependiera de la mera voluntad de los ciudadanos. Este carácter adquiere mayor relevancia en aspectos como la contratación internacional y la celebración de contratos por medios electrónicos, como quiera que, al tratarse de normas de orden público, su aplicación no puede ser soslayada so pretexto de la libertad contractual que existe en las relaciones privadas internacionales. Nótese, además, que instrumentos internacionales, como la Convención de Viena de 1980, deja por fuera de su ámbito de aplicación las compraventas internacionales celebradas con consumidores.

\section{g. Tiene fundamento constitucional}

El artículo 78 de la Constitución Política estipula la necesidad de la regulación del control de calidad de bienes y servicios ofrecidos y prestados a la comunidad, así como la información que debe suministrarse al público en su comercialización. Asimismo, se refiere a la responsabilidad de los productores y comercializadores que atenten contra la salud, seguridad y el adecuado aprovisionamiento a consumidores y usuarios. Este postulado ha tenido un desarrollo por parte de la Corte Constitucional. Al respecto, esta alta corporación manifestó en su sentencia C-1141 de 2000:

La Constitución ordena la existencia de un campo de protección en favor del consumidor, inspirado en el propósito de restablecer su igualdad frente a los productores y distribuidores, dada la asimetría real en que se desenvuelve la persona que acude al mercado en pos de la satisfacción de sus necesidades humanas. Sin embargo, la Constitución no entra a determinar los supuestos específicos de protección, tema este que se desarrolla a través del ordenamiento jurídico. El programa de protección, principalmente, se determina a partir de la ley, los reglamentos y el contrato. Es claro que la fuente contractual debe interpretarse de conformidad con los principios tuitivos del consumidor plasmados en la Constitución. Con el Derecho 
del consumidor se presenta algo similar de lo que se observa con otros derechos constitucionales. La Constitución delimita un campo de protección, pero el contenido preciso del programa de defensa del interés tutelado, es el que se desarrolla y adiciona por la ley y por otras normas y fuentes de reglas jurídicamente válidas. En particular, trazado el marco constitucional, a la ley se confía el cometido dinámico de precisar el contenido específico del respectivo Derecho, concretando en el tiempo histórico y en las circunstancias reales el nivel de su protección constitucional. El significado de un determinado derecho y su extensión, por consiguiente, no se establece sólo por la Constitución $a$ priori y de una vez para siempre.

La Corte Constitucional, en la sentencia C-973 de 2002, justifica la protección al consumidor desde el siguiente punto de vista:

La Constitución en relación con ciertas categorías de personas-menor, adolescente, anciano, mujer cabeza de familia, trabajador, indigente etc.- dispone un tratamiento de especial protección. En unos casos se persigue reforzar el respeto a la dignidad de la persona humana, sobre todo tratándose de personas que se encuentran en situación de debilidad manifiesta o que por su condición de extrema fragilidad pueden ser objeto de abusos por los demás. En otros casos, la Constitución aspira, con el régimen de especial protección, a avanzar sostenidamente el ideario de igualdad sustancial inherente al Estado social de derecho. Con sus particularidades, la Constitución ha querido instaurar un régimen de protección en favor del consumidor y usuario de bienes y servicios que circulan en el mercado.

Como ya se ha expresado, la razón de ser de este régimen estriba en la necesidad de compensar con medidas de distinto orden la posición de inferioridad con que consumidores y usuarios, por lo general dispersos y dotados de escasos conocimientos y potencialidades, enfrentan a las fuerzas de la producción y comercialización de bienes y servicios, necesarios en orden a la satisfacción de sus necesidades materiales. Cuando la Constitución encomienda al legislador el desarrollo de un cierto régimen de protección, no está simplemente habilitando una competencia específica para dictar cualquier tipo de normas. Lo que el Constituyente se propone es que la finalidad de la protección efectivamente se intente actualizar y se imponga en la realidad política y social -por lo menos en un grado razonable y en la medida de las posibilidades y recursos existentes-, articulando de la manera más armoniosa y eficaz dentro de las políticas públicas las justas demandas de los sujetos merecedores de dicha protección especial.

Se observa entonces que el carácter proteccionista del Derecho del consumo está plenamente justificado por la Corte, así como la consideración de los consumidores como una categoría de sujetos dignos de protección, lo que descarta cualquier asomo de duda con respecto a la razón de ser y carácter de este Derecho.

Por otro lado, los derechos de los consumidores pueden ser tutelados de manera individual o colectiva según la Constitución Política, que permite que mediante las acciones de grupo se pueda demandar la defensa de los intereses de los consumidores. Se evidencia así que los consumidores constituyen una nueva categoría de individuos en el Derecho moderno, tal y como son considerados los comerciantes o los trabajadores. 
La consagración constitucional de la protección a los consumidores es un fenómeno generalizado y hoy, en gran número de cartas fundamentales, se propende por la protección de esta categoría de individuos. Por ejemplo, en la Constitución argentina, el artículo 42 dispone que "Los consumidores y usuarios de bienes y servicios tienen derecho, en la relación de consumo, a la protección de la salud, seguridad e intereses económicos; a una información adecuada y veraz; a la libertad de elección y a condiciones de trato equitativo y digno". La Constitución peruana de 1993, en su artículo 65, expresa que "el Estado defiende los intereses de los consumidores y usuarios". El artículo 51 de la Constitución española de 1978 establece que el Estado garantizará la defensa de los consumidores y usuarios y protegerá la seguridad, la salud y los legítimos intereses económicos de los mismos.

Se advierte en forma clara cómo el artículo 78 de la colombiana consagra los postulados fundamentales del Derecho del consumo: el deber de información y el deber de seguridad que tienen los productores frente a los consumidores. Estos dos principios constituyen hoy en día la columna vertebral de la protección a los consumidores y se relacionan con los derechos que tradicionalmente se han reconocido a los consumidores (a ser informado, a la seguridad, el derecho a asociarse y el de ser escuchado), así como se verá a continuación.

\section{ÁMBITO DEAPLICACIÓN}

El amplio espectro de las situaciones cubiertas por el Derecho del consumo hace inútil enunciar los aspectos cobijados por el mismo, pues en todo tipo de situación o de relación jurídica en que se encuentren en juego intereses de los consumidores, el Derecho del consumo hace presencia. Sin embargo, a renglón seguido se enuncian y explican brevemente los pilares fundamentales del Derecho del consumo, alrededor de los cuales gira su campo de cobertura, a saber, los deberes de los productores y los derechos de los consumidores.

\section{a. Dos deberes básicos de los productores \\ El deber de información}

Este principio en Colombia tiene un carácter constitucional, ya que el artículo 78 de la Constitución Política se refiere a la necesidad de regulación de la información que se suministra al público en la comercialización de bienes y servicios. El deber de información consiste, básicamente, en que el productor tiene la obligación de dar información veraz, suficiente y clara al consumidor acerca de las características, utilidad, forma de utilización, contraindicaciones, $y$, en general, sobre todo aquello que le permita tomar una decisión consciente acerca de la necesidad de adquirir un bien o servicio que se le ofrece y le evite eventualmente un perjuicio. El deber de información cobija aspectos como la publicidad engañosa, la veracidad de los contenidos de las etiquetas y embalajes de los productos, la indicación debida de precios al consumidor y el consentimiento informado, entre otros. El estatuto colombiano de protección al consumidor regula algunos de estos aspectos, en lo referente a marcas, leyendas y propagandas (artículo 14), propagandas con imágenes (artículo 15), propagandas con incentivos (artículo 16), precios máximos al público (artículo 18) y regulación a la fijación de precios (artículos 19-22).
Se advierte en forma clara cómo el artículo 78 de la colombiana consagra los postulados fundamentales del Derecho del consumo: el deber de información yel deber de seguridad que tienen los productores frente a los consumidores. 
Elproductor

debe velar

porque los

bieneso

servicios que

ingrese al

mercado no

atenten contra

la salude

integridad

de los

consumidores,

bajo la pena de

indemnizar los

perjuicios que

se le causen.
Al llevar estos aspectos al campo contractual, se tocan aquellos que tienen que ver con la formación del consentimiento en la celebración de un negocio jurídico, como quiera que la falta de veracidad o la omisión de la información no permiten al consumidor emitir una manifestación de voluntad libre y espontánea. En casos especiales se necesita que esa manifestación de voluntad sea, además, ilustrada; es decir, que el productor debe cerciorarse de informar debidamente al consumidor sobre algunos aspectos, para lo cual debe alcanzar nuevos grados de formalismo, so pena de que el acto jurídico quede privado de eficacia. Un ejemplo de esto se da en el ordenamiento jurídico francés en la celebración de préstamos para la compra de vivienda, que incluye obligaciones de información, tiempos de retracto o de reflexión y la obligación de menciones manuscritas.

\section{El deber de seguridad}

El productor debe velar porque los bienes o servicios que ingrese al mercado no atenten contra la salud e integridad de los consumidores, bajo la pena de indemnizar los perjuicios que se le causen. En tal sentido, los productores son responsables de la idoneidad y calidad de los bienes o servicios que ofrezcan (artículo 23 del Estatuto del Consumidor). Este punto ha sido tal vez aquel que mayor impacto ha generado en la sociedad, como quiera que algunos bienes o productos defectuosos han causado perjuicios irremediables a un sinnúmero de personas. El caso de la sustancia talidomida en Alemania es uno de ellos.

Se podría pensar que se trata de un aspecto jurídico que se regula por las reglas generales de la responsabilidad civil, pero el legislador ha optado por crear unas reglas especiales de responsabilidad para estos casos. Se habla de responsabilidad civil por productos defectuosos. El Estatuto del Consumidor colombiano se refiere específicamente a la garantía mínima presunta (artículos 11 y 29), otras garantías (artículos 12, 13 y 29), la solidaridad entre productor y vendedor en tratándose de bienes importados (artículo 23), responsabilidad por información no veraz (artículo 31), causales de exoneración de la responsabilidad (artículos 26 y 27), fuerza mayor (artículo 30) e indemnización de perjuicios (artículos 36, 37 y 40).

\section{b. Los derechos de los consumidores}

En el año 1962, el presidente Kennedy, en su famoso discurso, propuso cuatro derechos básicos de los consumidores, que aún perduran: el derecho a la información, a la seguridad, a ser escuchado y a escoger. Sin embargo, a raíz del desarrollo que el tema ha tenido en todo el mundo en las últimas décadas, se han promovido otros derechos de los consumidores. Por ejemplo, una directiva de la onu de 1985 promueve los siguientes derechos de los consumidores: protección frente a los riesgos de la salud y la seguridad, acceso a la información adecuada, posibilidades de educación efectiva entre consumidores, educación y libertad para formar grupos u organizaciones de consumidores (Durand, 2007: 115). En este orden de ideas, se puede decir que los principales derechos de los consumidores que se promueven en la actualidad son:

Derecho a ser informado

A la seguridad

A asociarse

A ser escuchado de manera individual y colectiva 
A la reparación de daños y perjuicios

A un medio ambiente sano

A la revocación (o retracto)

A la igualdad de trato (no discriminación)

A la libre elección de bienes y servicios

A la protección de sus intereses económicos

A la educación.

Alrededor de estos deberes y derechos se circunscribe el ámbito de aplicación del Derecho del consumo, lo que de entrada permite afirmar que es bastante amplio y no es fácil de delimitar, pues en cualquier relación jurídica que estén en juego intereses de los consumidores se procurará la defensa de estos mediante sus normas especiales.

\section{El Derecho del CONSUMOY Yel dereCHO cONTRACTUAL}

En materia de relaciones contractuales, el Derecho del consumo aboga por la protección de la parte débil de la relación jurídica obligacional entre productor y consumidor, denominada relación de consumo, lo cual se ha traducido en normas de protección a la formación del consentimiento, como el deber de información y el derecho de retracto, la interpretación contra proferentem, la interpretación favor debilis o pro consumidor, la regulación de contratos de adhesión o condiciones generales de contratación, la prohibición de cláusulas abusivas y la regulación de cláusulas de exoneración y limitación de la responsabilidad con consumidores, entre otras.

En el Derecho colombiano, algunos de estos aspectos todavía tienen una regulación muy precaria, contrario a lo que sucede en algunos ordenamientos jurídicos, como el comunitario europeo, en el cual se ha llevado el tema de la protección al consumidor, influido por una perspectiva social, a un grado de desarrollo bastante alto. En Colombia, por ejemplo, en el tema de contratos de adhesión, una sola norma regula este aspecto: el artículo 1624 del Código Civil. Así mismo, en lo atinente a cláusulas abusivas no existe ningún tipo de regulación y la jurisprudencia al respecto es casi inexistente. Todo lo anterior hace pensar que la legislación colombiana está rezagada en la regulación de estos temas, pues no siempre los principios generales del Derecho privado son suficientes para solucionar problemas que hace cien años eran insospechados.

\section{CONCLUSIONES}

El Derecho del consumo es de reciente aparición y responde a las necesidades de las situaciones de mercado del mundo actual. En algunos ordenamientos jurídicos, sobre todo en economías de países desarrollados, ha tenido un avance importante, mientras en otros, como el colombiano, ha tenido un desarrollo lento y los progresos que se presentan son demasiado tímidos.

El estatuto de protección al consumidor colombiano data de 1982, pero, a pesar de que regula aspectos como el deber de información y el deber de seguridad de los productores, esta norma merece ser remozada para ponerse a tono con aspectos cruciales del Derecho moderno. En tiempos en que se predica la inserción del país en la economía internacional y la integración económica en sus diferentes niveles, ya sea en tratados de libre comercio o la inserción en bloques económicos (uniones aduaneras o mercados comunes), el país debe contar con un ordenamiento jurídico que le permita
El Derecho del consumo es de reciente aparición y responde a las necesidades de las situaciones de mercado del mundo actual. 
Es un Derecho de carácter tuitivo que ha tenido plena aceptación en diferentes ordenamientos jurídicos para proteger a la nueva categoría de ciudadanos que son los consumidores. ingresar de manera adecuada a estos contextos, sobre todo protegiendo a sus ciudadanos en situaciones de mercado que se vuelven cada día más complejas. Es entonces cuando la legislación se debe revisar para que sea idónea en temas como la protección al consumidor, el Derecho de la competencia y las normas de propiedad intelectual, entre otros.

El Derecho del consumo encuentra su razón de ser en la necesidad de proteger las relaciones jurídicas que en algunas situaciones son asimétricas, como la relación consumidor-productor. Es un Derecho de carácter tuitivo que ha tenido plena aceptación en diferentes ordenamientos jurídicos para proteger a la nueva categoría de ciudadanos que son los consumidores. Así como existe un Derecho del trabajo para los trabajadores, existe un Derecho del consumo para los consumidores.

El Derecho del consumo tiene una fisonomía propia, que lo distingue de otras ramas o perspectivas del Derecho, y su grado de importancia se revela en que la protección a los consumidores es un imperativo de orden constitucional en muchos ordenamientos jurídicos. Gracias a diferentes medios, la protección al consumidor es una realidad en muchos Estados; y en niveles de integración económica es indispensable contar con normas que respondan a las necesidades de mercados comunes.

El Derecho del consumo se inmiscuye en diferentes áreas del Derecho; no es Derecho público ni privado. Aun así, se puede eviden- ciar más proximidad con el Derecho privado, como quiera que las relaciones jurídicas que se consideran de consumo se configuran, en su gran mayoría, entre personas naturales o jurídicas de naturaleza privada.

En el área del Derecho privado rompe con esquemas y postulados del Derecho clásico contenido en códigos decimonónicos. Implica una restricción a principios como la autonomía de la voluntad, porque el legislador se entromete en las relaciones jurídicas de los particulares, de tal forma que al consumidor se le debe informar, no se le pueden incluir cláusulas abusivas y, en algunos casos, se puede retractar del negocio a pesar de haberlo perfeccionado. Conlleva igualmente un replanteamiento del Derecho contractual, porque cuando existe una relación de consumo varían algunas normas aplicables al negocio jurídico. En fin, se trata de una perspectiva jurídica que revoluciona el Derecho y que en la enseñanza de este no se puede dejar de lado. Un curso de obligaciones, contratos, Derecho comercial, entre otros, debe incluir temas de Derecho del consumo.

Los principios del Derecho del consumo, los deberes de los productores, los derechos de los consumidores, así como los aspectos contractuales del Derecho del consumo, son bastante amplios y en algunas ocasiones complejos, por lo cual merecen un tratamiento aparte y más juicioso. En este artículo, a manera de introducción al Derecho del consumo, tan solo se pretendió hacer mención de ellos, con la finalidad de esbozar los alcances de este nuevo Derecho.

\section{BIBLIOGRAFÍA}

- Alpa, Guido. (2004). El Contrato en el derecho privado italaiano actual. Perú :Ara Editores.

- Calais-Auloy, J. (2006). Droit de la consommation (7. éd.). Paris: Dalloz. 
- Durand Carrión, J. (2007). Tratado de Derecho del consumidor en el Perú (1.a ed.). Lima: Universidad San Martín de Porres.

- González Vaqué, L. (2007). Las nociones de consumidor medio y miembro de un grupo particular de consumidores en el Reglamento 1924/2006. Gaceta Jurídica de la Unión Europea y de la Competencia. 247: 9-19.

- Ghersi, C.A. (2002). Contratos civiles y comerciales (tomo I, 5. ${ }^{\mathrm{a}}$ ed.). Buenos Aires: Editorial Astrea.

- Márquez Robledo, F. (2007). Apuntes de Derecho económico y de la competencia (2. ${ }^{\mathrm{a}}$ ed.). Bogotá: Universidad Javeriana.

- Mosset Iturraspe, J. y Lorenzetti R.L. (1993). Defensa del consumidor. Buenos Aires: Rubinzal-Culzoni Editores.

- Ovalle Favela, José. (2000). Comentarios a la ley federal de protección al consumidor, México: Mc Graw-Hill.

- Pérez Bustamante, L. (2004). Derechos del consumidor, Buenos Aires: Editorial Astrea.

- Poillot, E. (2006). Droit européen de la consommation et uniformisation du droit des contrats. Paris: LGDJ.

- Rivero Sánchez, J.M. (1997). ¿Quo Vadis. Derecho del consumidor? Medellín: Biblioteca Jurídica Diké.

- Rubio Escobar, J. (2007). Derecho de los mercados. Bogotá: Legis.

- Taormina, G. (2004). Théorie et pratique du droit de la consommation Aiex en Provence: Editeur Librairie de l'Université d'Aix en Provence.

- Velilla, M.A. (2001). Introducción al Derecho de los negocios. Bogotá: El Navegante Editores y Ediciones Jurídicas Gustavo Ibáñez. 